\title{
Development of a Prediction Model for Lifespan Reduction Based on the Freezing and Thawing of Cement Paste Composite Material Considering Seasonal Environment
}

\author{
Do-Gyeum Kim, Myung-Sug Cho, Jong-Suk Lee, and Hojae Lee
}

\begin{abstract}
As for the methods to evaluate the resistance to freezing and thawing of concrete, ASTM C 666 method 4.3 rapid freezing and thawing test method is mostly used globally. However, few researches are conducted about the relation between accelerated freezing and thawing test of ASTM C 666 test method and the freezing and thawing under natural environment at the moment. In this research, therefore, the researcher intends to develop a technique to predict the reduction of durability of actual concrete structure that experiences freezing and thawing under irregular temperature condition by examining the method to calculate the result of indoor accelerated test that receives freezing and thawing under regular temperature condition and by examining the method to calculate correspondence coefficient from the weather data located in the actual structure.
\end{abstract}

Index Terms-Concrete, freeze thaw, durability, prediction model.

\section{INTRODUCTION}

Generally, concrete structures can be affected directly or indirectly by various weather conditions such as rain, wind, snow, sun and so forth. Due to these things, contraction and expansion occur by freezing and thawing (F-T), temperature change and repeated drying and wetting. Among them, freezing and thawing are repeated in winter and can reduce the durability of concrete in a long term. As for the reduction of durability of concrete due to freezing and thawing, the moisture inside the concrete structure gets frozen and thawed repeatedly causing cracks or destruction of the surface layer and the durability of the concrete structure is compromised gradually from the surface.

As for the methods to evaluate the resistance to freezing and thawing of concrete, ASTM C 666 method 4.3 rapid freezing and thawing test method is mostly used globally. However, few researches are conducted about the relation between accelerated freezing and thawing test of ASTM C 666 test method and the freezing and thawing under natural environment at the moment.

The existing prediction models for lifespan reduction include the method to describe the relations between the

Manuscript received January 21, 2013; revised March 20, 2013.

Do-Gyeum Kim, Jong-Suk Lee, and Hojae Lee are with the Structural Engineering Research Division, Korea Institute of Construction Technology, South Korea (tel.: +82-31-910-0133, +82-31-910-0139, +82-31-910-0390; fax: +82-31-910-0715; e-mail: dgkim@kict.re.kr, jslee@kict.re.kr, h.lee@kict.re.kr)

Myung-Sug Cho is with the Plant Construction \& Engineering Laboratory, KHNP Central Research Institute, Korea Hydro \& Nuclear Power Co., LTD, South Korea (tel.: +82-42-870-5824; fax.: +82-42-870-5819; e-mail: concrete@khnp.co.kr) amount of freezing water, air void coefficient, amount of porosity and relative dynamic modulus of elasticit [1], [2]. However, there is a practical issue that special devices are needed to measure the amount of freezing water, air void coefficient and the amount of porosity. In addition, Ghaffori etc. made freezing and thawing reduction model based on the result of indoor freezing and thawing tests under regular temperature conditions. With such model, however, it would be difficult to consider the actual natural environment, in which temperature conditions are irregular.

In this research, therefore, the researcher intends to develop a technique to predict the reduction of durability of actual concrete structure that experiences freezing and thawing under irregular temperature condition by examining the method to calculate the result of indoor accelerated test that receives freezing and thawing under regular temperature condition and by examining the method to calculate correspondence coefficient from the weather data located in the actual structure.

\section{EXAMINATION OF THE EXISTING MODEL FORMULA}

\section{A. Emperical Model}

Shuman's Model Formula - Shuman[3] stated that the resistance to freezing and thawing can be expressed by the reduction of dynamic modulus of elasticity due to AE amount, water-cement ratio and the reduction of dynamic modulus of elasticity of concrete based on the number of freezing and thawing cycles. According to the experiential result, he reported that the change of dynamic modulus of elasticity has the tendency of straight line when the number of freezing and thawing cycles exceeds 50. In Shuman's model formula, annual strength reduction RFT (based on the faction of strength loss) is expressed as follows,

$$
R_{h}=\left(N / T_{C}\right)\left[0.05 / \theta^{1 / 2}-0.21 T_{r}\right]
$$

where,

$N$ : Number of freezing and thawing cycles

$T_{c}$ : Experiment period that is needed for dynamic modulus of elasticity to be reduced by $50 \%$

$\theta$ : Amount of moisture in concrete

$T_{r}$ : Amount of unsaturated porosity

Ghafoori's Model Formula - Based on the freezing and thawing experiment about concrete blocks for paving according to ASTM C 666 A method (underwater freezing, underwater thawing) Ghafoori [4] suggested the following mass reduction prediction formulas with such variables as the 
amount of cement, density and compressive strength.

- Formulas with the amount of cement as a variable

$$
\begin{aligned}
L M= & 0.586(C C)-14.655(C Y C+C C) \\
& +9.024 \frac{\sqrt{C Y C}}{\sqrt{C C}}-\frac{284.033}{C Y C}+3828
\end{aligned}
$$

- Formulas with the density as a variable

$$
\begin{aligned}
L M= & 142.5 \frac{\sqrt{D E N}}{C Y C}+\frac{5631.5}{D E N}-383.6 \frac{\ln (D E N)}{\ln (C Y C)} \\
& -0.057 \sqrt{(C Y C)(D E N)}+207
\end{aligned}
$$

- Formulas with the compressive strength as a variable

$$
\begin{aligned}
L M= & -4.014 \sqrt{C Y C}+0.018 \sqrt{(C Y C)(C M P)} \\
& +256.017 \frac{\sqrt{C Y C}}{\sqrt{C M P}}-6.289
\end{aligned}
$$

where,

$$
\begin{aligned}
& L M: \text { Mass reduction ratio }(\%) \\
& C C: \text { Cement amount }\left(\mathrm{lb} / \mathrm{yd}^{3}\right) \\
& D E N: \text { Density }\left(\mathrm{lb} / \mathrm{ft}^{3}\right) \\
& C M P: \text { Compressive strength (psi) } \\
& C Y C: \text { Number of freezing and thawing cycles }
\end{aligned}
$$

\section{B. Mathematical Model}

As stated above, most of the existing model formulas related to the resistance to freezing and thawing are composed experientially based on the result of freezing and thawing tests, As the freezing and thawing of actual structures is affected externally by lowest freezing temperature, thawing temperature, duration of lowest freezing temperature, moisture state, wind condition and so forth and also affected internally by many things such as the type and state of material, water and cement ratio, amount of air, amount of water, unit amount, curing condition and so forth. it is almost impossible to modeling such complex actions mathematically.

The elements considered in the existing model formula for predicting lifespan reduction due to freezing and thawing. The existing model formulas can be divided prediction formulas about the reduction of dynamic modulus of elasticity and the prediction formulas about mass reduction. The formulas about the reduction of dynamic modulus elasticity are mainly formulas that predict the reduction of durability inside the concrete due to freezing and thawing, and the formulas about mass reduction are mainly formulas that predict the reduction of durability on the surface of the concrete due to the combined work of freezing and thawing and salt water.

Most of the existing model formulas are composed based on the result of indoor accelerated freezing and thawing tests under regular freezing temperature conditions. Therefore, it is difficult for such models to consider the actual natural environment, in which temperature conditions are irregular. In order to predict the lifespan reduction of actual structures under irregular temperature conditions precisely due to freezing and thawing, therefore, it is necessary to compose a model that considers the natural environment, in which the lowest freezing temperatures are irregular.

\section{COMPOSITION OF THE BASIC MODELS}

\section{A. Basic Model}

As stated above, most of the existing prediction models for life span reduction due to freezing and thawing are made under regular temperature conditions and therefore it is very difficult to predict the reduction of durability of actual concrete structure due to freezing and thawing under the natural environment, in which temperature conditions are irregular. In other words, as the lowest temperature condition for freezing in the indoor accelerated freezing and thawing, the force that creates a damage equivalent to a single cycle of freezing and thawing is the same. Under natural environment, however, as the lowest temperature for freezing is irregular, the force that creates damage per cycle affects the concrete irregularly. In order to predict the lifespan reduction of actual structures precisely due to freezing and thawing, it is necessary to make a formula that can consider the irregular lowest temperatures for freezing.

The temperature elements that can affect the reduction of durability due to freezing and thawing include lowest temperature for freezing, freezing speed, thawing temperature, duration of the lowest temperature for freezing and so forth. In this research, however, only the lowest temperature for freezing that is believed to have the biggest effect is considered. That is because the temperature elements such as freezing speed, thawing temperature and the duration of the lowest temperature for freezing are considered to have little effect on the resistance to freezing and thawing in the temperature range under natural environment [5-7] The methods to evaluate the reduction of durability due to freezing and thawing includes change of strength, change of length, change of mass and so forth. In this research, however, change of strength of concrete was focused and relative dynamic modulus of elasticity is used, which is generally used to represent the reduction process of concrete durability in freezing and thawing test.

In this research, the model [8] will be adopted as the basic model formula for predicting lifespan reduction due to freezing and thawing. This model formula predicts the destruction cycle with the variables of the lowest temperature for freezing and water and cement ratio based on the result of rapid underwater freezing and underwater thawing test with ASTM C 666 A method [9] and the mixture of Non-AE concrete. Here, the definition of destruction cycle is the number of cycles, at which the relative dynamic modulus of elasticity becomes less than $60 \%$.

$$
N=10^{\{0.14 \ln (C / W)+0.004\} \theta+3.15 \ln (C / W)+1.43}
$$

where,

$N$ : Number of destruction cycles

$\theta$ : Lowest temperature

$C / W$ : Cement-Water ratio

The result of predicting a certain cement-water ratio and the number of destruction cycle in the lowest freezing temperature using equation (5) was shown in Fig.1. In other words, with equation (5), the number of destruction cycle that corresponds to a certain water-cement ration and the lowest temperature for freezing can be gained. 


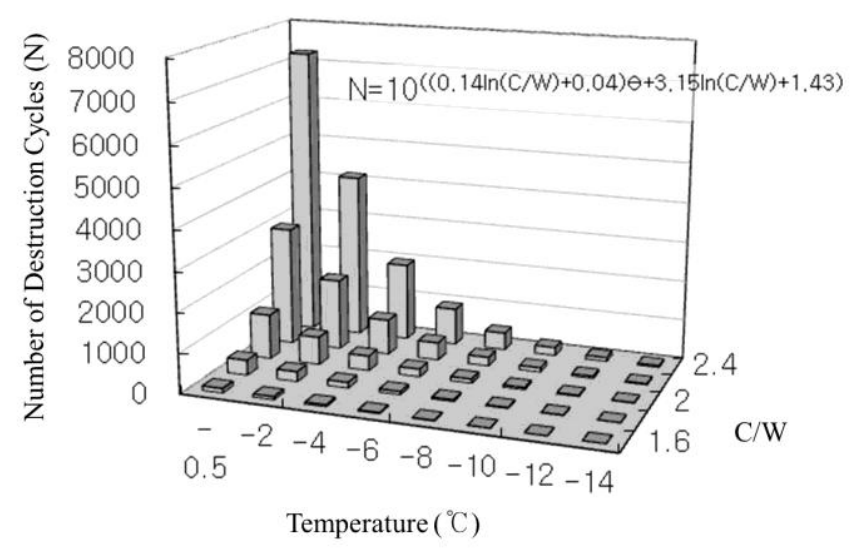

Fig.1. Lowest Temperature and Water-Cement Ratio that Affect the Destruction Cycle

\section{B. Calculation of the Number of F-T under Nature}

Under natural environment, the lowest outside temperature affects the concrete irregularly. As the lowest temperature is regular in the indoor accelerated test, the force that creates the damage that is equivalent for a single cycle of freezing and thawing. Under natural environment, however, the force that creates damage per each cycle affects the concrete irregularly as the lowest temperature changes. In addition, the calculation of the number of freezing and thawing cycles under natural environment can be gained with equation (5) as long as there is a measured result about the field inspection and the concrete exposed in the field. However, there is no measurement result of field inspection or exposure test about the reduction of durability due to freezing and thawing at nuclear power plant structures

In this research, however, the researcher intends to suggest the calculation technique to gain the number of freezing and thawing cycles that can consider the irregular lower temperatures for freezing under natural environment based on the result of indoor freezing and thawing test.

\section{Calculation of Annual Average Number of F-T Cycles}

Concrete is generally frozen at a temperature slightly lower than $0{ }^{\circ} \mathrm{C}$, and the freezing temperature differs slightly according to the alkali density of the concrete, chloride density of the concrete and so forth [8]. In this researcher, as the freezing temperature differs for each type of concrete, freezing and thawing occurs at $0{ }^{\circ} \mathrm{C}$ and the frequency of freezing and thawing is calculated per the lowest freezing temperature of $0.5^{\circ} \mathrm{C}$ in order to simplify the arrangement of weather data. With the above assumption, annual average number of freezing and thawing cycles is calculated equation (6)

$$
N F T_{a v .}=\frac{\sum\left(N T_{i} \times T_{i}\right)}{T_{a v .}}
$$

where,

$N F T_{a v}$ : Annual average freezing and thawing cycles

$N T_{i}$ : Number of freezing and thawing cycles at the lowest freezing temperature $i$

$T_{i}$ : Lowest freezing temperature calculated per $0.5^{\circ} \mathrm{C}$

$T_{a v}$ : Annual average lowest temperature for freezing

\section{Calculation of Corresponding Coefficient $(K)$}

The following corresponding coefficient is calculated from the result of indoor accelerated freezing and thawing test under a certain temperature condition in order to apply the result of indoor accelerated freezing and thawing test to the concrete structure under natural environment and from the weather data of the location, in which the actual concrete structure is located.

$$
K=\frac{N}{N F T_{a v}}
$$

Calculate the number of freezing and thawing cycles in the actual natural environment that corresponds to the number of freezing and thawing cycles of the indoor accelerated freezing and thawing test.

$$
N_{n a}=K \times N_{r o}
$$

where,

$N_{n a}$ : Number of freezing and thawing cycles under natural environment

\section{$K$ : Corresponding coefficient}

$N_{r o}$ : Number of freezing and thawing cycles in the indoor accelerated freezing and thawing test

\section{E. Relation between Relative Dynamic Modulus of Elasticity and the Number of Freezing and Thawing Cycles}

The relation between the relative dynamic modulus of elasticity gained from indoor accelerated freezing and thawing test and the number of freezing and thawing cycles gained under natural environment can be estimated by regression analysis in the form of (9)

$$
R_{e d}=100 \operatorname{Exp}\left(\alpha \times N_{n a}\right)
$$

where,

Red: Relative dynamic modulus of elasticity

$a$ : Variable

Here, the variable 1 is the coefficient that changes by concrete mixture and environmental condition.

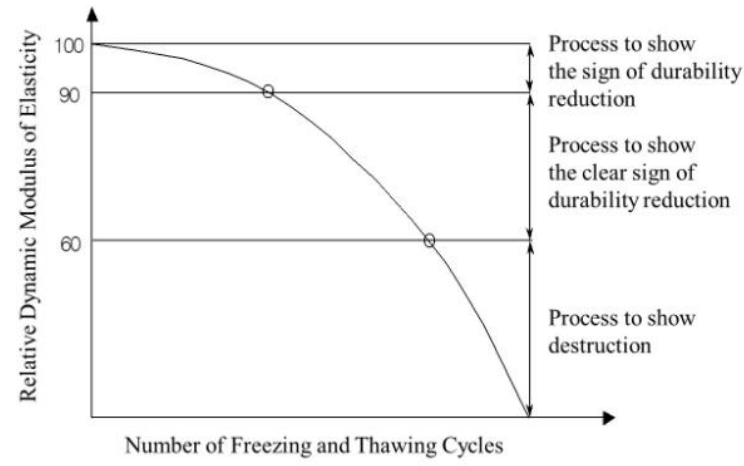

Fig. 2. Figure about the Process of Durability Reduction due to Freezing and Thawing

Fig. 2 shows the standard to judge the reduction of durability due to freezing and thawing For the judgment about the reduction of durability, $90 \%$ of relative dynamic modulus of elasticity was classified as the process to show the sign of the reduction of durability, $90 \%$ to $60 \%$ of relative dynamic modulus of elasticity was classified as the process to show clear sign of the reduction of durability and less than $60 \%$ of relative dynamic modulus of elasticity was classified as the process to show the destructive state of the concrete. Here, concrete with less than $90 \%$ of relative dynamic modulus of 
elasticity is at the level where maintenance is required.
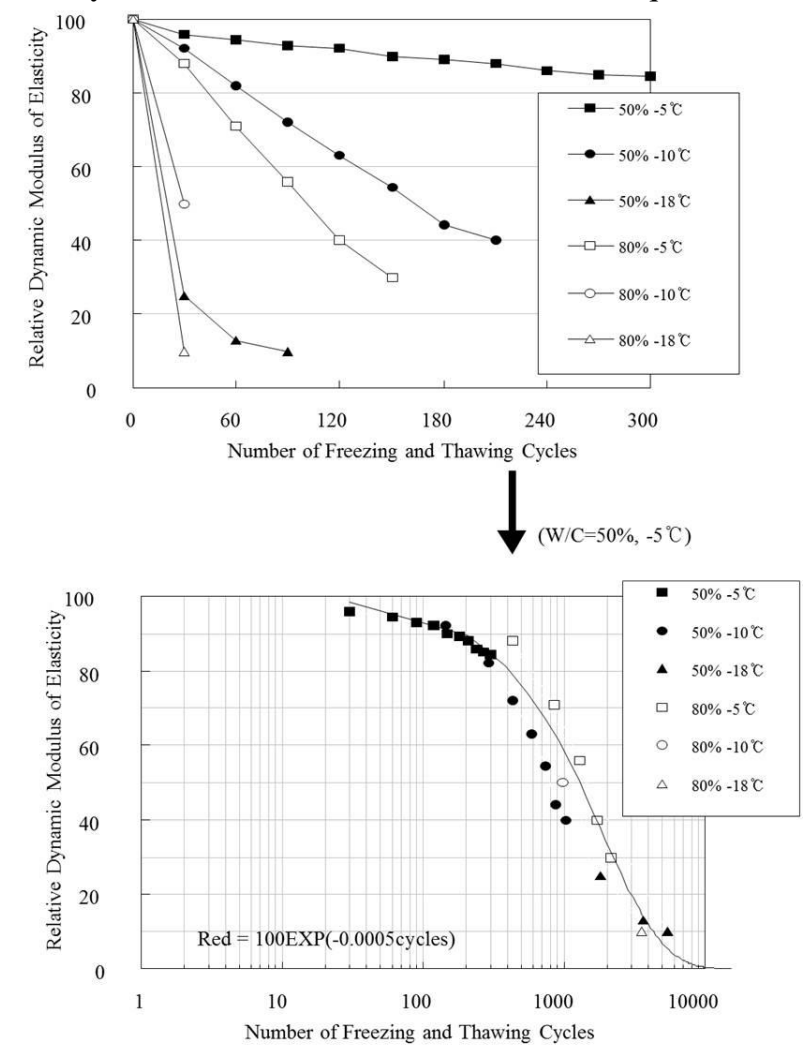

Fig. 3. Effect of Water-Cement Ratio and the Lowest Temperature for Freezing

\section{Configuration of Prediction Model of Life Span DEGRADATION}

Fig. 3 shows the result of applying equation (9) with the standard of the destruction cycle with $50 \%$ of water-cement ratio and $-5^{\circ} \mathrm{C}$ of lowest freezing temperature for the result of the accelerated freezing and thawing test with the variables such as water-cement ratio and the lowest freezing temperature. As a result, the relation between standardized number of freezing and thawing cycles and the relative dynamic modulus of elasticity can be expressed as a single durability reduction curve regardless of the water-cement ratio or the lowest freezing temperature. For example, 90 cycles of the concrete with $50 \%$ of water-cement ratio and $-18{ }^{\circ} \mathrm{C}$ of the lowest freezing temperature and the concrete with $80 \%$ of water-cement ratio and $-5{ }^{\circ} \mathrm{C}$ of the lowest freezing temperature can be estimated to be 4,600 cycles and 1,150 cycles in the standardized freezing and thawing cycle. In other words, it can be estimated that about 50 time of durability reduction occurs when the water-cement ratio is $50 \%$ and the lowest freezing temperature changes from $-5^{\circ} \mathrm{C}$ to $-18^{\circ} \mathrm{C}$ and 13 times of durability reduction occurs for the concrete with $80 \%$ of water-cement ration compared to the cement with $50 \%$ of water-cement ratio when the lowest freezing temperature is $-5^{\circ} \mathrm{C}$.

Fig. 3 shows the result of the destruction cycle when the water-cement ratio is $49 \%$ about the result of the freezing and thawing test with water-cement ratio as a variable under the condition of $-18{ }^{\circ} \mathrm{C}$ of the lowest freezing temperature. According to this result, compared to the concrete with $49 \%$ of water-cement ratio at the point of 300 freezing and thawing cycle, the concrete with $71 \%$ of water-cement ratio shows 950 cycles, which is about 3 times, the concrete with $91 \%$ of water-cement ratio shows 1,400 cycles, which is about 4.7 times and the concrete with $101 \%$ of water-cement ratio shows 4,200 cycles, which is about 14 times more reduction of durability.

From the above results, by using the concept of standardized freezing and thawing cycle, the concrete durability reduction curve due to freezing and thawing can be estimated under a certain water-cement ratio and the lowest temperature condition for freezing.

\section{ACKNOWLEDGMENT}

This work was supported by the Nuclear Research \& Development of the Korea Institute of Energy Technology Evaluation and Planning(KETEP) grant funded by the Korea government Ministry of Knowledge Economy. (No. 2011T100200161)

\section{REFERENCES}

[1] E. Kamada and O. Senbu, "Statistical investigation concerning the effects of pore structure on the frost resistance of concrete," Journal Structure and Construction Eng., AIJ, no. 487, 1994.

[2] F. S. Rostasy, R. U. Weiss, and G. Wiedeman, "Changes of pore structure of cement mortars due to temperature," Cement and Concrete Research, vol. 18, no. 5, 1988.

[3] R. Shuman, V. V. Rogers, and R. A. Shaw, "The barrier code for predicting long-term concrete performance," Waste Management 89, University of Arizona, 1989.

[4] N. Ghaffori and R. Mathis, "Prediction of freezing and thawing durability of concrete paving blocks," Journal of Materials in Civil Engineering, no. 45, 1998.

[5] K. Ishi and H. Noguchi, "Prediction of concrete deterioration by cyclic freezing and thawing," JSCE, vol. 36, no. 571, 1997.

[6] K. T. Koh and T. Miura, "The lowering of quality and countermeasure of various types of concrete due to initial frost damage," Cement and Concrete Technology, no. 52, 1998.

[7] M. Pigeon and R. Pleoau, "Durability of concrete in cold climates," $E$ \& FN SPON, 1995.

[8] T. Fujiwara, "Deterioration of concrete used in road bridges due to freezing and thawing, Katharine and Bryant Mather International Conference an concrete durability," ACI Special Pubication SP-100, 1987.

[9] ASTM C 666-84, "Standard test method for resistance of concrete to rapid freezing and thawing," Annual Book of ASTM Standards, vol. 04, no. 02, pp. 403-410, 1984.

Do Gyeum Kim is a research fellow in Structural Engineering Research Division, Korea Institute of Construction Technology(KICT), Republic of Korea. He received his $\mathrm{BSc}, \mathrm{MSc}$ and $\mathrm{PhD}$ in Chungnam National University, Republic of Korea. His research concerns the durability of concrete structures in terms of corrosion of steel in concrete, ionic transport and microstructure analysis of concrete.

Myung-Sug Cho is a research fellow in the Plant Construction \& Engineering Laboratory, KHNP Central Research Institute, Korea Hydro \& Nuclear Power Co., LTD, South Korea. His research interest covers high performance concrete development and seismic engineering of Nuclear Power Plant structures.

Jong-Suk Lee is a senior researcher in Structural Engineering Research Division, Korea Institute of Construction Technology(KICT), Republic of Korea. He received his BSc, MSc and PhD in Hanyang University, Republic of Korea. His research concerns the durability of NPP(Nuclear Power Plant) concrete structures, structural analysis of concrete structure.

Ho Jae Lee is a researcher in Structural Research Division, Korea Institute of Construction Technology(KICT), Republic of Korea. He received his MSc in Yonsei University, Republic of Korea. His research interest covers cement chemistry, corrosion of steel in concrete and its quantitative evaluation. 